\title{
The use of WeChat in higher education: Investigation of Chinese students in Australia
}

\author{
Daeyoung Kim, Shanton Chang \\ The University of Melbourne
}

\begin{abstract}
With the increasing popularity of social technologies, many Chinese students use WeChat for their studies in Australia. However, there have been limited studies about how students effectively use WeChat for their academic activities and the impacts on students' academic achievements. Therefore, this study focuses on the relationship between WeChat usage and academic activities of university students in Australia. Using a modified Delphi technique, we conducted three online focus groups of 16 university students who had an experience of WeChat. A thematic analysis revealed that the usage of WeChat could impact their academic performance, and many international students had challenges to be familiarised with a new digital environment in Australia. The findings contribute to much clear understanding of how students utilise WeChat for academic activities to provide a better usage of social media for university students.
\end{abstract}

Keywords: WeChat, SNS, higher education, academic, relationship

\section{Introduction}

Australia had the second-largest percentage of international tertiary students (27\%) and the third-highest number of international students $(445,000)$ within the OECD countries in 2018 (OECD, 2020). Also, the number of Chinese students' enrolments has rapidly increased from 2012 to 2019 in Australia (Hinton, 2020). A crucial part of understanding this phenomenon is the growing discussion about supporting their studies overseas more efficiently (Arkoudis et al., 2013; Chang \& Gomes, 2017). With Chinese students making up a large cohort of students, there has been increased interest in the experiences of Chinese international students (Heng, 2019; Henze \& Zhu, 2012). This paper is particularly interested in using Social Networking Services (SNS) by Chinese international students to enhance their academic experiences while in Australia.

There have been studies on the adaption of social media for academic work in higher education (Cooper \& Naatus, 2014; Hamat et al., 2012). For example, Dunn (2013) and Legaree (2015) have stated the importance of understanding the usage of SNS because many students have been using it not only for socialising or entertainment reasons but also for their studies. Furthermore, some research addressed several advantages to using social media in higher education (Dunn, 2013; Gregory et al., 2014; Legaree, 2015). The principal benefits of using SNS for academic activities include peer learning, improving communication, expanding collaboration, promoting critical thinking and self-directed learning (Dunn, 2013; Legaree, 2015). However, the earlier studies also pointed out drawbacks and limitations using social media for teaching and learning (Chakraborty et al., 2013; Walsh et al., 2013). The main concerns of using SNS are security and privacy leaking issue, copying their ideas, and time management. Nevertheless, there is a lack of research on examining the disadvantage of social media to overcome it for supporting students' academic activities.

There was also research to examine the effectiveness of WeChat for academic work in higher education. A study revealed that the use of WeChat could improve students' knowledge effectively in medical education (Wang et al., 2017). However, compared to the prominent English social media, less research has been done on SNS that are used primarily in another language (e.g., Chinese) such as WeChat. Also, there was no clear answer about how much WeChat can impact on their academic achievements and what kinds of difficulties they are having in their studies.

This paper investigates the status and limitation of WeChat usage for academic work in higher education. From the investigation, this study aims to make a clear understanding of how university students utilise WeChat to do academic activities. Therefore, the primary research question of this study is: "How do students use WeChat in helping them with their studies in higher education?" After finding out a clear answer about the question, in conclusion it will suggest a better usage of social media for their academic achievement. 


\section{Literature Review}

\subsection{Social Media for Academic Work}

Previous research addressed several advantages to using social media in higher education. The main benefits include the following: (i) improving communication between students and academics, (ii) expanded the chances for collaboration with students, (iii) prompt information sharing with classmates, (iv) referring to the course material after the lecture, (v) supplement of the learning management systems, and (vi) the development of technical skill leading to employability (Dunn, 2013; Legaree, 2015).

However, in addition to the benefits, there are also some challenges in relation to the use of social media for academic work. One of the significant challenges of using social media in higher education is protecting security and privacy while sharing information (Zhang \& Xie, 2020). The disadvantages of using social media are that many students struggle with time management, and ICT skills are required to use social media more effectively (Heo et al., 2021). It means that we need to investigate more precisely what kinds of activities have made a negative impact on students' studies and try to find out a solution for overcoming these limitations. Therefore, when examining the use of social media in academic work, it is important to consider both the benefits and challenges in order to advise students on the best way to support students.

\subsection{Social Media for Peer Learning}

In the literature, it emphasises the importance of peer learning in online education. For example, a study revealed that online peer feedback had several advantages, like the possibility of acquiring valuable learning skills for the contributor (Popta et al., 2017). Also, Broadbent and Poon (2015) found that online peer learning could make a meaningful positive effect on students' academic achievements. It implicates that the interaction among students is an essential part to support their learning effectively not only in the classroom but also in online education.

Nevertheless, the literature inclines to focus on specific functionalities of social media. From a review of research area on online teaching and learning from 2009 to 2018, it pointed out that the research on course design and development was not thoroughly examined in the online education area (Martin et al., 2020). Furthermore, The Finding Common Ground Project (Arkoudis et al. 2013) indicated that there was limited interaction between domestic and international students in higher education, that had to be supported more systematically. From the study, it suggested the implementation of 'The Interaction for Learning Framework (ILF)', that recognised key factors for curriculum design by academics. Even though the report stated that the growing interaction between domestic and international students had excellent benefits in teaching and learning, the previous study did not provide a clear answer about how the idea can be realised in the online teaching \& learning environment. Recent studies such as Chang et al. (2021) have focused on websites as sources of information but not looked at social media. Therefore, it is required to examine if social media could provide the primary role to enhance the interaction between students to support their academic activities through the online environment.

\subsection{WeChat in Higher Education}

There were previous studies that investigated the usage of WeChat in the educational environment. A study stated that a short period of training through WeChat could improve nurses' knowledge and perspective effectively (Wang et al., 2017). Also, WeChat is actively used for the self-education of college students (Wei and $\mathrm{Ke}, 2014)$. It explained that WeChat could motivate undergraduate students to learn the contents actively in political education. In a study about the effectiveness of language exchange through WeChat, it reported that there was a significant result to support the language learning between Chinese and English speaking students (Wang et al., 2016). Also, Xu et al. (2020) mentioned that WeChat could be generally used to promote educational group discussions.

However, compared to the major English social media, less research has been done on SNS used primarily in another language like WeChat and often used informally by students. Pang (2018) mentioned that there were comparatively fewer experiential investigations on WeChat usage of undergraduate students. A study revealed that WeChat has so many useful functionalities, but many international students in China do not utilise them properly due to the language problem (Zhu \& Chhachha, 2016). It gives the idea that there might be a similar 
challenge for international students in Australia to be adapting to the new English digital environment overseas (Chang \& Gomes, 2017). Therefore, this paper seeks to understand how university students utilise WeChat for their academic activities, such as doing assignments or group discussion.

\section{Research Methodology}

\subsection{Research Method}

This research is related to students' experience of WeChat usage for their academic activities. Consequently, the empirical research approach could be more suitable to find out the interpretive results of users' experiences. Also, the qualitative data analysis might give us much rich information to understand students' real experience of WeChat. Therefore, in order to answer the research question, it took a modified Delphi technique as the research methodology in this study. The Delphi is a reliable method for examining an aspect when there is inadequate information or insufficient agreement among societies (Kezar \& Maxey, 2016).

The alternative method to answer the research questions could be Focus Group Interview (FGI) because one of the most popular ways of data acquisition in qualitative research is the interview and focus groups (Gill et al., 2008). Therefore, this study had a mixed approach to collect both survey data and FGI as the modified Delphi method. The combined research method can provide a better understanding of the problem and much deep \& wide information which the sole use of method could not find or miss out (Almalki, 2016; Doyle et al., 2009). Moreover, it is helpful that the Delphi technique merges quantitative and qualitative methods to secure a sufficient level of opinions for the Delphi steps (Fink-Hafner et al., 2019). Consequently, the modified Delphi technique with FGI is considered the most suitable approach to achieve the research goal.

\subsection{Data Samples \& Collection}

The total participants of this project were sixteen students from different universities. They were divided into three groups with five, five, and six students for each FGI, respectively. There was no age limitation, and it had recruitment from a wide range of demographics and academic disciplines. Also, as an expert of WeChat users, the participants must have experience using WeChat and were willing to attend the survey and group discussion. For anonymity reasons, the FGI participants were identified by using their focus group names (e.g., FG1-FG3) and the order of attendees (e.g., P1-P6) in the online group discussion. For example, FG3-P5 represents the fifth participant of the third focus group. The demographic information of research participants is depicted in table 1.

Table 1. Demographic information of research participants in each focus group

\begin{tabular}{|c|c|c|c|c|c|c|c|}
\hline $\begin{array}{l}\text { Focus } \\
\text { Group } \\
(\mathbf{n}=\mathbf{3})\end{array}$ & $\begin{array}{l}\text { No. of } \\
\text { Students } \\
\text { \& Gender }\end{array}$ & $\begin{array}{l}\text { Degree } \\
\text { Program }\end{array}$ & Major Course & $\begin{array}{l}\text { Country of } \\
\text { Birth }\end{array}$ & $\begin{array}{l}\text { Previous } \\
\text { Country of } \\
\text { Education }\end{array}$ & $\begin{array}{l}\text { Residency } \\
\text { Period in } \\
\text { Australia }\end{array}$ & $\begin{array}{l}\text { Age } \\
\text { (Years) }\end{array}$ \\
\hline FG1 & $\begin{array}{l}\text { Total: } 5 \\
\text { Male: } 2 \\
\text { Female: } 3\end{array}$ & $\begin{array}{l}\text { Bachelor: } 3 \\
\text { Master: } 2 \\
\text { PhD: } 0\end{array}$ & $\begin{array}{l}\text { Software Development, } \\
\text { Secondary Education, } \\
\text { Theology, Linguistics }\end{array}$ & $\begin{array}{l}\text { China: } 4 \\
\text { Australia: } 1\end{array}$ & $\begin{array}{l}\text { China: } 3 \\
\text { U.S.A.: } 1 \\
\text { India: } 1\end{array}$ & $\begin{array}{l}\text { 0-1 Year: } 0 \\
\text { 1-5 Year: } 4 \\
\text { 5-9 Year: } 0 \\
\text { 10- Year: } 1\end{array}$ & $\begin{array}{l}\text { 17-20: } 0 \\
\text { 21-25: } 4 \\
\text { 26-30: } 1\end{array}$ \\
\hline FG2 & $\begin{array}{l}\text { Total: } 5 \\
\text { Male: } 2 \\
\text { Female: } 3\end{array}$ & $\begin{array}{l}\text { Bachelor: } 0 \\
\text { Master: } 5 \\
\text { PhD: } 0\end{array}$ & $\begin{array}{l}\text { Information Systems, } \\
\text { Sociology, Linguistics, } \\
\text { Secondary Education }\end{array}$ & $\begin{array}{l}\text { China: } 4 \\
\text { Taiwan: } 1\end{array}$ & $\begin{array}{l}\text { China: } 3 \\
\text { Taiwan.: } 1 \\
\text { U.S.A: } 1\end{array}$ & $\begin{array}{l}\text { 0-1 Year: } 0 \\
\text { 1-5 Year: } 4 \\
\text { 5-9 Year: } 1 \\
\text { 10- Year: } 0\end{array}$ & $\begin{array}{l}\text { 17-20: } 0 \\
\text { 21-25: } 2 \\
26-30: 3\end{array}$ \\
\hline FG3 & $\begin{array}{l}\text { Total: } 6 \\
\text { Male: } 2 \\
\text { Female: } 4\end{array}$ & $\begin{array}{l}\text { Bachelor: } 5 \\
\text { Master: } 1 \\
\text { PhD: } 0\end{array}$ & $\begin{array}{l}\text { Law, Econometrics, } \\
\text { Materials Engineering, } \\
\text { Tourism Management, } \\
\text { Computer Science, } \\
\text { Linguistics }\end{array}$ & $\begin{array}{l}\text { China: } 4 \\
\text { Hong Kong: } 1 \\
\text { Indonesia: } 1\end{array}$ & $\begin{array}{l}\text { China: } 4 \\
\text { Hongkong: } 1 \\
\text { Indonesia: } 1\end{array}$ & $\begin{array}{l}\text { 0-1 Year: } 1 \\
\text { 1-5 Year: } 5 \\
\text { 5-9 Year: } 0 \\
\text { 10- Year: } 0\end{array}$ & $\begin{array}{l}\text { 17-20: } 3 \\
\text { 21-25: } 3 \\
\text { 26-30: } 0\end{array}$ \\
\hline
\end{tabular}

As for the data collection process, this study had the following three stages:

- Stage 1: We recruited sixteen university students who had the experience of using WeChat. They were 
divided into three focus groups with five, five and six students in each group, respectively. An initial survey was sent out to all the students. There were four open questions in the survey that asked for users' usage experience on WeChat. The survey had questionnaires about the primary purpose of using SNS, the performance of WeChat for academic works, the experiences of using WeChat for academic activities, and the preference of SNS for study.

- Stage 2: When all the survey results of each group came back, the researcher summarised them and sent the summary report to each relevant focus group. All the participants of FGI should fully understand the survey summary report before the online conference to discuss it in the focus group.

- Stage 3: We organised an online conference (e.g., Zoom meeting) with each group to see whether they agreed or disagreed with a specific idea during the group discussion. There were three groups using the same process. In this final group interview stage, the researcher added additional questions with the original interview questions. After then, it checked if they had different ideas or agreed to a particular opinion during the group discussion.

\subsection{Data Analysis}

The data analysis was conducted to get the answer to the research question from the survey results and transcripts of three FGI. In this study, the collected data were evaluated by using thematic coding manually. Thematic analysis is a process to gain significant ideas and explore a typical model of experience by segmenting, classifying, and summarising qualitative data set (Gibbs, 2007; Given, 2008). It is also an excellent strategy to understand the participants' ideas and experiences from a qualitative data set, such as interview transcripts or survey replies (Nowell et al., 2017).

Firstly, all of the FGI transcripts were carefully read several times to find out common opinions and agreements of the participants. If there was a specific idea which the group broadly agreed or disagreed on, the idea was defined with a short name and definition (Given, 2008). After then, similar ideas were clustered to become a common idea. There were 27 common ideas in the first phase of the analysis. In the second phase, the initial common ideas were reviewed with the research supervisor to mitigate subjectivity bias and share the opinions about the analysis with each other. Based on the feedback, the common ideas were appropriately updated with the right names and definitions. Also, similar common ideas were merged, and the low-level ideas were classified to belong under the high-level common ideas. Moreover, the participants' quotes of the interview transcripts were carefully evaluated to interpret the meaning of common ideas correctly in the coding (Nowell et al., 2017). In the end, this study confirmed 15 common ideas by the refining processes.

At the last phase of the data analysis, it made a group of similar common ideas to be a theme and gave a proper name and definition to the theme. Similar common ideas were considered to be sub-themes of the key theme. After then, we checked how many times the sub-themes were mentioned in the transcripts. Also, all of the themes were reviewed with the supervisor to evaluate the right name and level of them. In order to identify key themes, this study had the analysis processes several times while looking back at the transcripts again and again. From the analysis, it could find out the four key themes with 15 sub-themes.

\section{Findings}

From the data analysis, the identified four key themes and 15 sub-themes were summarised with the explanation in the following table 2. All of these themes and sub-themes are the most common opinions which many university students agreed or disagreed on regarding their usage patterns of social media. Each of them will be described more below with examples of students' quotes from FGI data. 
Table 2. Themes for the usage pattern of social media by university students

\begin{tabular}{|c|c|c|}
\hline Key Themes & Sub-Themes & $\begin{array}{l}\text { Number of } \\
\text { students } \\
\text { who agreed } \\
(\mathrm{n}=16)\end{array}$ \\
\hline \multirow{3}{*}{$\begin{array}{l}\text { Theme 1) There is a } \\
\text { diversity of use and } \\
\text { adoption of SNS for } \\
\text { multiple purposes }\end{array}$} & 1a) SNS is an essential part of Students' Academic work & 6 \\
\hline & 1b) Students use SNS for sharing information on employment & 4 \\
\hline & 1c) Students use SNS for socialising and entertainment & 5 \\
\hline \multirow{5}{*}{$\begin{array}{l}\text { Theme 2) } \\
\text { Communication } \\
\text { patterns of Chinese } \\
\text { international } \\
\text { students using } \\
\text { WeChat can impact } \\
\text { on their academic } \\
\text { achievements }\end{array}$} & 2a) Over usage of WeChat impact on students' academic performance negatively & 14 \\
\hline & 2b) The quality of group member affects the context of group communication & 6 \\
\hline & $\begin{array}{l}\text { 2c) Students recognise that continued use of Chinese SNS does not help to improve } \\
\text { their English skill }\end{array}$ & 11 \\
\hline & 2d) The advantage of familiarity with the home country's social media & 8 \\
\hline & 2e) Students actively exchange academic ideas with group members by WeChat & 13 \\
\hline \multirow{4}{*}{$\begin{array}{l}\text { Theme 3) Students' } \\
\text { transition between } \\
\text { Chinese and English } \\
\text { SNS is important } \\
\text { for academic } \\
\text { performance }\end{array}$} & 3a) Chinese international students adopt new English media apps while in Australia & 10 \\
\hline & 3b) Chinese international students do not encourage local students to use WeChat & 3 \\
\hline & 3c) Majority rule for the selection of group SNS & 6 \\
\hline & 3d) Students need some guidance about how to utilise SNS for academic work & 3 \\
\hline \multirow{3}{*}{$\begin{array}{l}\text { Theme 4) There are } \\
\text { functionalities of } \\
\text { WeChat for } \\
\text { Consideration }\end{array}$} & 4a) Concern about the security of WeChat & 5 \\
\hline & 4b) Audio \& Video Chat in WeChat is useful functionality for students & 6 \\
\hline & 4c) A calendar functionality on SNS could be useful for students & 6 \\
\hline
\end{tabular}

\subsection{Theme 1: Diversity of use and adoption of SNS for multiple purposes}

Based on the analysis of students' quotations, this study could find out that students utilised social media not only for just communication or socialising reasons but also for multiple purposes such as academic activities and sharing useful information. There are three sub-themes under theme 1.

- Sub-Theme 1a: SNS is an essential part of Students' Academic work: Many students thought that the role of SNS was essential for their academic work. They also used SNS for the academic topic at the university rather than for social or entertainment things. One of the Chinese students replied:

FG3-P5: "If I am using social media within Uni, entertainment is not one of them because it is entirely for academic purposes. For outside of Uni, I usually use it for communication and for networking and also for entertainment as well."

- Sub-Theme 1b: Students use SNS for sharing information on employment: In addition, students utilised WeChat for sharing information on employment. It points to idea that social media is also useful to share specific information such as employment between students. A student mentioned as below:

FG3-P5: "As WeChat is also used for employment purposes, I had some personal experience which I was hired as a group where we had all the staffs together, and we would share the latest news and just happening in the company, or anything we needed to take a note off and the current trend for a just like normal meeting with a client."

- Sub-Theme 1c: Students use SNS for socialising and entertainment: Some of the students agreed that they spent a lot of time with SNS for socialising and entertainment as one of the prime reasons. From the survey results, the average time which many students spend on SNS was 2-3 hours a day. 


\subsection{Theme 2: Communication patterns of Chinese students using WeChat}

From the data analysis, it shows that communication patterns of Chinese international students using WeChat can impact on their academic achievements. It points the idea that the usage of WeChat could affect their academic results positively or negatively. Even though Chinese international students have benefit from connecting easily to many Chinese using WeChat in Australia, they also require the desirable usage of WeChat to utilise it properly for their group studies. There are five sub-themes in theme 2 .

- Sub-Theme 2a: Over usage of WeChat impact on students' academic performance negatively: Regarding student's usage time of WeChat, the analysis found that the overuse of WeChat could impact on students' academic achievements negatively. 14 of 16 students agreed to this opinion (the highest scored idea). This result also points out that time management is one of the key issues of WeChat usage for students. For example, one of the students explained:

FG3-P3: " I think if I can't use any of them, I think I can pay more attention and spend more time in study."

- Sub-Theme 2b: The quality of group member affects the context of group communication: Also, students thought the quality of group members could affect the context of group communication. It means that students need to know how to organise a group with a proper usage of SNS to support their academic activities much efficiently. As an example, a student stated:

FG1-P4: "So, I think it's really depending on whether your friends see the space as more academically reaching and they would post something around it which actually refashion this space to something else."

- Sub-Theme 2c: Students recognise that continued use of Chinese SNS does not help to improve their English skill: One of the interesting findings from the analysis is many Chinese students recognised that the continued use of Chinese SNS did not help to improve their English skill. One of the Chinese students mentioned:

FG2-P4: "I think WeChat can help you to do the teamwork. It won’t improve your English because you were always typing in Chinese."

- Sub-Theme 2d: The advantage of familiarity with the home country's social media: There are some benefits for Chinese international students to utilise WeChat for their study because it is the largest platform in the Chinese community and easy to connect with other Chinese students in Australia. Therefore, they can get useful information much easier for their study and life overseas through WeChat than other English media apps.

- Sub-Theme 2e: Students actively exchange academic ideas with group members by WeChat: It means that students proactively utilise WeChat to do group assignments or discussions in order to collaborate with their group members efficiently. 13 of 16 students agree to this idea (the 2nd highest scored opinion). For example, one of the students explained their usage of WeChat as below:

FG3-P6: "For academic purposes, I use WeChat to discuss questions with my classmates and discuss topics or share files with my group members."

\subsection{Theme 3: Students' transition between Chinese and English SNS}

By the data analysis results, it discloses that students' transition between Chinese and English SNS has influenced on their study in Australia. It means that many Chinese international students are having the challenges to be adapting to a new English digital environment with the need for proper guidance. There are four sub-themes under this theme.

- Sub-Theme 3a: Chinese international students adopt new English media apps while in Australia: It seems that many Chinese international students expand their accessibility of SNS to the English media apps like Facebook Messenger for better communication with local or other international students. One of the Chinese students said:

FG3-P4: "I think messenger is better than WeChat because I am studying in an English environment. So, all my PS and majority of classmates are not in WeChat. And also, Messenger has better functionality as I can see if the other people have seen my message or not."

- Sub-Theme 3b: Chinese international students do not encourage local students to use WeChat: It points to the idea that students are not staying on a particular SNS and trying to select suitable SNS for better communication with classmates depending on their situation.

- Sub-Theme 3c: Majority rule for the selection of group SNS: Chinese international students choose social 
media which many group members already have for the group chat. For an example of quotations, A student said:

FG1-P2: "If everyone... most people use messenger, we use messenger. If most people use

WhatsApp, we use WhatsApp. If we have multi people who use WeChat, but not using other

platforms, yeah I may be encouraging them to be used."

- Sub-Theme 3d: Students need some guidance about how to utilise SNS for academic work: It points out that the universities are required to provide students with the proper usage of Social Medias for their studies.

\subsection{Theme 4: Functionalities of WeChat for Consideration}

From the analysis of the results, we found there are pros and cons to the functionalities of WeChat. As bad features, this study realised that the current issue of 'security and information reliability of WeChat' could be a big drawback for students to utilise social media more actively in their study. However, WeChat has some convenient services such as QR code, Audio \& Video chat, and Voice messenger to help students' academic activities. Also, some functionalities such as a calendar are requested by students in order to support their academic activities more efficiently. There are three sub-themes under this key theme.

- Sub-Theme 4a: Concern about the security of WeChat: Despite the useful functionalities in WeChat, Chinese students expressed anxiety about privacy and information reliability with WeChat. It could be a drawback of using SNS for students' academic activities eventually. For example, A Chinese student said:

FG3-P3: "But just like somehow many things come to my concern about a security issue or many about the reliability of news or general articles share through WeChat. Because I always find the big difference between new or information form WeChat and the different other social media, so I think it will be something that I really concerned about. "

- Sub-Theme 4b: Audio \& Video Chat in WeChat is useful functionality for students: Many students said that Audio \& Video Chat in WeChat was a useful service for them to communicate easily with classmates. It looks they utilised the functionality for the group discussion frequently. As for an example, one student mentioned:

FG2-P2: "I think ... regarding academic activities when I was using WeChat or other social media, I used Video Chat instead of typing it. From experience I found, it can be more efficient, and people are present, and discussions are more productive."

- Sub-Theme 4c: A calendar functionality on SNS could be useful for students: Furthermore, there were suggestions to improve the usability of WeChat to support students' studies. One of them was the idea of the implementation of calendar functionality into WeChat. This points the idea that students feel the necessity of social media for sharing their idea with others more efficiently to support their academic activities.

\section{Discussion}

\subsection{Relationship between WeChat and Academic Activities}

This study revealed that students actively exchanged academic ideas with group members to do group assignments by WeChat. It means that students use not only university provided tools, but also several public online tools together to do their studies productively. From the findings, we can understand that students utilise WeChat with diverse online tools extensively for their academic activities such as group assignments, group discussions, and sharing ideas in higher education.

Based on the analysis of results in findings, many university students in Australia considered SNS as an important social technology to support not only for socialising or entertainment but also for their academic reasons. They used SNS for the academic topics at the university rather than for socialising or entertainment things. It supports the evidence of the earlier study, which introduced the survey result on Malaysian University students' use of SNS for the purpose of informal learning (Hamat et al., 2012).

\subsection{Digital Transition and the Use of WeChat for Academic Work}

There might be some critical reasons why Chinese international students need to keep using WeChat in Australia. As the first reason, they had the advantage of familiarity with the home country's social media. Therefore, there were benefits for Chinese international students to utilise WeChat for their studies more comfortably than other SNS because WeChat was the largest platform in the Chinese community and easy to 
connect with other Chinese students in Australia. As the previous study stated (Bonyhady, 2019), they still depended on WeChat much for collecting or sharing information with classmates overseas in the reason. For the second reason, they prefer WeChat to get or share information easily without language barriers and to keep in touch with the home country's friends frequently. As the last reason, the much effort and less familiarity with a new digital environment could make them stay in their home country's social media of WeChat rather than other SNS. This study complements that many previous studies addressed several reasons for the continuing use of social media by international students (Bonyhady, 2019; Chang \& Gomes, 2017; Mao, 2014).

Despite the usefulness of WeChat, many students agreed that how they use the platform could impact on their academic performance (Gregory et al., 2014). Firstly, the overuse of WeChat gave them a negative result by distracting them from their studies. This finding supports the evidence of the time management issue of students, which was reported from the earlier study as the limitation of social media (Hamid et al,. 2011). Secondly, the quality of group members affected the context of group communication. Therefore, they needed to know how to organise a group with proper usage of SNS to support their academic activities productively. Lastly, many Chinese international students already recognised that the continued use of Chinese social media was not helpful for them to improve their English ability. As to this finding, the research result contrasts the idea of the previous study that WeChat could make a meaningful contribution to support the language exchange between Chinese and English speaking students (Wang et al., 2016). It could be assumed that the different results came from the differentiation of research environment settings. Based on the research results on their usage patterns of WeChat, this study found we needed to provide some guidelines to improve student usage of SNS for their academic activities in the right method.

\subsection{Functionalities of WeChat}

From a technical point of view, this study could understand WeChat had useful functionalities to support students' study. QR Code Scanner was a convenient functionality for students to share their information easily with classmates. Many students said that Audio \& Video Chat in WeChat were useful tools for group discussions. Also, the service of Voice Messaging was helpful for students to leave a short message to classmates quickly without typing it.

However, there was also a serious concern about the security of WeChat. Many Chinese students are worried about privacy and information reliability with WeChat. As the previous study already pointed it as one of the critical issues for using social media (Chakraborty et al., 2013), It could be a disadvantage of using WeChat for students to do academic activities at the end. Furthermore, there were some suggestions to improve the usability of WeChat to support students' studies. Some students said that a calendar function could be helpful for students to manage their schedules and tasks with group members more efficiently through WeChat. Also, other students requested that sharing resources on the screen in WeChat would be useful to support their academic work.

\subsection{Limitation of the Study}

In this study, it recruited 16 university students to participate in the research. There was difficulty in recruiting enough participants due to the COVID-19 pandemic in 2020. Therefore, most of the research processes, including the focus group interviews, were conducted through the online environment this time because of the social distancing reason. Although there were some limitations, this research contributed valuable data to develop more enhanced knowledge and understanding into the use of WeChat for academic purposes. If it could increase the number of participants for the study, it might expect the more accurate and diverse ideas of WeChat users in the university. Otherwise, a quantitative survey with a considerable number of respondents may generate different results and hidden findings.

\subsection{Suggestion for Future Research}

As for the suggestion for future research, it feels the need to compare this result with cases of Chinese students in other countries. For example, there are already many Chinese background local students who are using WeChat in Singapore. In that kind of case, we may need to investigate how the Chinese international students use WeChat for their studies with the local or other international students. It may give us a more profound and broad understanding of the digital journey of international students, which was introduced by previous research (Chang \& Gomes, 2017). 
Moreover, based on the understanding of the current situation of Chinese international students in Australia, it recommends the development of a proper online learning model of social media to support both international and domestic students for their academic activities. As previous studies introduced the potential of peer-to-peer learning through social media (Dalsgaard, 2014), future research can find the solution from improving the peer learning between international and domestic students through the online environment by the development of a particular framework such as the Interaction for Learning Framework (Arkoudis et al., 2013).

\section{Conclusion}

This study investigated the relationship between WeChat usage and academic activities in higher education from the students' perspective. In order to answer the research question, the findings provide a comprehensive explanation of how university students use WeChat in helping them with their studies. This research reflected the opinions of university students who came from various academic disciplines and levels of study. Consequently, the research results in this study imply the standard point of view of the university students who are using WeChat. As the study is also examined based on students' real experience on WeChat, the findings contribute to the improvement of empirical research results that are relevant to providing the usage of social media for university students. From the findings, this study could help our understanding of WeChat usage more clearly. One of the significant findings is that the communication patterns of Chinese international students using WeChat could impact their academic achievements. It indicates that they need proper usage of WeChat for Chinese international students in Australia. Also, this study reinforces that many international students are having the challenges to be adapting to new English media apps with the need for proper guidance of it. This finding contributes to the significance of a digital transition of international students.

\section{References}

Almalki, S. (2016). Integrating Quantitative and Qualitative Data in Mixed Methods Research--Challenges and Benefits. Journal of Education and Learning, 5(3), 288-296. https://eric.ed.gov/?id=EJ1110464

Arkoudis, S., Watty, K., Baik, C., Yu, X., Borland, H., Chang, S., Lang, I., Lang, J., \& Pearce, A. (2013). Finding Common Ground: Enhancing Interaction between Domestic and International Students in Higher Education. Teaching in Higher Education, 18(3). https://doi.org/10.1080/13562517.2012.719156

Bonyhady, N. (2019). Chinese Students in Australia Are Living in a New Media Landscape. The Sydney Morning Herald. https:/www.smh.com.au/politics/federal/chinese-students-in-australia-are-living-in-a-newmedia-landscape-20190830-p52md9.html

Broadbent, J., \& Poon, W. L. (2015). Self-Regulated Learning Strategies \& Academic Achievement in Online Higher Education Learning Environments: A Systematic Review. Internet and Higher Education, 27, 1-13. https://doi.org/10.1016/j.iheduc.2015.04.007

Chang, S., \& Gomes, C. (2017). Digital Journeys: A Perspective on Understanding the Digital Experiences of International Students. Journal of International Students, 7(2), 347-366.

Chang, S., Gomes, C., Platt, M., Trumpour, S., McKay, D., \& Alzougool, B. (2021). Mapping the contours of digital journeys: a study of international students' social networks in Australian higher education. Higher Education Research \& Development, DOI: 10.1080/07294360.2021.1962812

Cooper, B., \& Naatus, M. K. (2014). LinkedIn as a Learning Tool in Business Education. American Journal of Business Education, 7(4), 299-306. https://doi.org/10.19030/ajbe.v7i4.8815

Dalsgaard, C. (2014). Students' Use of Facebook for Peer-to-Peer Learning. Proceedings of the 9th International Conference on Networked Learning 2014, 95-102.

Doyle, L., Brady, A.-M., \& Byrne, G. (2009). An Overview of Mixed Methods Research. Journal of Research in Nursing, 14(2), 175-185. https://doi.org/10.1177/1744987108093962

Dunn, L. (2013). Teaching in Higher Education: Can Social Media Enhance the Learning Experience? In: 6th Annual University of Glasgow Learning and Teaching Conference, Glasgow, UK.

Fink-Hafner, D., Dagen, T., Dou`sak, M., Novak, M., \& Hafner-Fink, M. (2019). Delphi Method: Strengths and Weaknesses. Metodolo ski zvezki, 16(2), 1-19. https://www.researchgate.net/publication/337570516

Gibbs, G. R. (2007). Thematic Coding and Categorizing in Analyzing Qualitative Data. London: SAGE Publications. https://dx.doi.org/10.4135/9781526441867.n4

Gill, P., Stewart, K., Treasure, E., \& Chadwick, B. (2008). Methods of Data Collection in Qualitative Research: Interviews and Focus Groups. British Dental Journal, 204, 291-295.

Given, L. M. (2008). Thematic Coding and Analysis. in The Sage Encyclopedia of Qualitative Research Methods. Thousand Oaks: SAGE Publications. 
Gregory, P., Gregory, K. \& Eddy, E. (2014). The Instructional Network: Using Facebook to Enhance Undergraduate Mathematics Instruction. Journal of Computers in Mathematics and Science Teaching, 33(1), 5-26. Waynesville, NC USA: Association for the Advancement of Computing in Education (AACE). https://www.learntechlib.org/primary/p/42123/

Hamat, A., Embi, M. A., \& Hassan, H. A. (2012). The Use of Social Networking Sites among Malaysian University Students. International Education Studies, 5(5), 56-66. https://eric.ed.gov/?id=EJ1066893

Hamid, S., Kurnia, S., Waycott, J., \& Chang, S. (2011). Exploring Malaysian Students' Perspectives of Online Social Networking (Osn) Use for Higher Education. Paper presented at the 22nd Annual Conference ISANA International Education Association (ISANA) 2011, Hobart, Tasmania.

Heng, T. (2019). Understanding the Heterogeneity of International Students' Experiences: A Case Study of Chinese International Students in U.S. Universities. Journal of Studies in International Education, 23(5), 607-623. https://doi.org/10.1177/1028315319829880

Henze, J., \& Zhu, J. (2012). Current Research on Chinese Students Studying Abroad. Research in Comparative and International Education, 7(1), 90-104. https://doi.org/10.2304/rcie.2012.7.1.90

Heo, H., Bonk, C. J., \& Doo, M. Y. (2021). Enhancing learning engagement during COVID-19 pandemic: Selfefficacy in time management, technology use, and online learning environments. Journal of Computer Assisted Learning, 1-13. https://doi.org/10.1111/jcal.12603

Hinton, T. (2020). Number of Chinese Student Enrolments in Australia from 2010 to 2019, by Education Sector (in 1,000s). Statista. https://www.statista.com/statistics/430276/number-of-chinese-students-in-australia-byeducation-sector/

Kezar, A., \& Maxey, D. (2016). The Delphi Technique: An Untapped Approach of Participatory Research. International Journal of Social Research Methodology, 19(2), 143-160.

Legaree, B. A. (2015). Considering the Changing Face of Social Media in Higher Education. FEMS Microbiology Letters, 362(16), 1-3. https://doi.org/10.1093/femsle/fnv128

Mao, C. (2014). Friends and Relaxation: Key Factors of Undergraduate Students' Wechat Using. Creative Education, 5, 636-640. DOI:10.4236/ce.2014.58075

Martin, F., Sun, T., \& Westine, C. D. (2020). A Systematic Review of Research on Online Teaching and Learning from 2009 to 2018. Computers \& Education, 159. https://doi.org/10.1016/j.compedu.2020.104009

Nowell, L. S., Norris, J. M., White, D. E., \& Moules, N. J. (2017). Thematic Analysis: Striving to Meet the Trustworthiness Criteria. International Journal of Qualitative Methods, 16, 1-13.

OECD. (2020). Education at a Glance 2020: Oecd Indicators. OECD Publishing. https://doi.org/10.1787/69096873-en

Pang, H. (2018). Wechat Use Is Significantly Correlated with College Students' Quality of Friendships but Not with Perceived Well-Being. Heliyon, 4(11). https://doi.org/10.1016/j.heliyon.2018.e0096 7

Popta, E. v., Kral, M., Camp, G., Martens, R. L., \& Simons, P. R.-J. (2017). Exploring the Value of Peer Feedback in Online Learning for the Provider. Educational Research Review (20), pp. 24-34.

Walsh, J. L., Fielder, R. L., Carey, K. B., \& Carey, M. P. (2013). Female College Students' Media Use and Academic Outcomes: Results from a Longitudinal Cohort Study. Emerging Adulthood, 1(3), 219-232.

Wang, F., Xiao, L. D., Wang, K., Li, M., \& Yang, Y. (2017). Evaluation of a Wechat-Based Dementia-Specific Training Program for Nursesin Primary Care Settings: A Randomized Controlled Trial. Applied Nursing Research, 38, 51-59. https://doi.org/10.1016/j.apnr.2017.09.008

Wang, Y., Fang, W.-C., Han, J., \& Chen, N.-S. (2016). Exploring the Affordances of Wechat for Facilitating Teaching, Social and Cognitive Presence in Semi-Synchronous Language Exchange. Australasian Journal of Educational Technology, 32(4). https://doi.org/10.14742/ajet.2640

Wei, H., \& Ke, L. (2014). "New Weapons" of Ideological and Political Education in Universities - Wechat. in: IFSRAP 2013 - The First International Forum on Studies of Rural Areas and Peasants. SHS Web of Conferences, 5. https://doi.org/10.1051/shsconf/20140604001

Xu, B., Chen, N., \& Chen, G. (2020). Effects of teacher role on student engagement in WeChat-Based online discussion learning. Computers \& Education, 157. https://doi.org/10.1016/j.compedu.2020.103956

Zhang, Y., \& Xie, H. (2020). Research on the Communication Mechanism and Influence of WeChat Official Platform in Colleges and Universities. Proceeding of International Conference on Education Studies: Experience and Innovation (ICESEI 2020), Russia, 493 (418-422). https://doi.org/10.2991/assehr.k.201128.078

Zhu, X. Y., \& Chhachha, A. R. (2016). Descriptive Analysis Regarding Use of Wechat among University Students in China. Asian Social Science, 12(2). http://dx.doi.org/10.5539/ass.v12n2p151 
Kim, D., \& Chang, S. (2021). The use of WeChat in higher education: Investigation of Chinese students in Australia. In Gregory, S., Warburton, S., \& Schier, M. (Eds.), Back to the Future - ASCILITE '21.

Proceedings ASCILITE 2021 in Armidale (pp. 219-229). https://doi.org/10.14742/ascilite2021.0133

Note: All published papers are refereed, having undergone a double-blind peer-review process.

The author(s) assign a Creative Commons by attribution licence enabling others to distribute, remix, tweak, and build upon their work, even commercially, as long as credit is given to the author(s) for the original creation.

(C) Kim, D., \& Chang, S. 2021 